\title{
Information Asymmetry among Multiple Principals and Inefficiency within the Organization
}

\author{
Kyung-Hye Kim ${ }^{1}$, Seung-Weon Yoo ${ }^{2}$ and Kyong-Soo Choi ${ }^{3, *}$ \\ 1 Department of Accounting, Daejeon University, 62 Daehak-ro, Dong-gu, Daejeon 34520, Korea; \\ khk1023@dju.ac.kr \\ 2 Korea University Business School, Korea University, 145 Anam-ro, Seongbuk-gu, Seoul 02841, Korea; \\ acyoo@korea.ac.kr \\ 3 Department of Business Administration \& Accounting, Hanbat National University, 125 Dongseodae-ro, \\ Yuseong-gu, Daejeon 34158, Korea \\ * Correspondence: kschoi1905@hanbat.ac.kr; Tel.: +82-042-821-1377
}

Received: 9 November 2019; Accepted: 3 December 2019; Published: 5 December 2019

\begin{abstract}
We develop a theoretical framework to investigate the effect of information asymmetry between the two principals on the common agent's incentives to provide an effort. We find that the agent's effort to the poorly-informed (PI) principal is optimal, while his effort to the well-informed (WI) principal is not. Given that the valuable resource, i.e., the agent's effort, should flow into the person who has higher ability, our results imply that the asymmetric information between two principals generates an efficiency loss within the organization. In addition, we examine whether this inefficiency is attenuated by changes of the relative weight of the agent's profit set to each principal. The result shows that unless the WI principal solely determines the agent's profit, the efficiency loss within the organization does not disappear. This finding corroborates that as long as the PI principal exists within the organization, the inefficiency might be inevitable. Our research not only provides new insights to the agency literatures but also offers useful information regarding the efficiency of organizational structure.
\end{abstract}

Keywords: poorly-informed principal; well-informed principal; inefficiency

\section{Introduction}

Organizations are characterized by various structures they possess. Among those, the matrix structure has been regarded as the primary organizational device for maintaining an efficient allocation of resources in multi-project environments [1]. The matrix structure, above all, is different from the other types of organizational structure in the sense that a subordinate must report to two or more superiors. Thus, if one views a subordinate as an agent and superiors as principals, the matrix structure can be described as an organization which is made up of a common agent and multiple principals.

Since the matrix structure often involves a multi-project setting where each of these multiple principals is in charge of her own project, the common agent may exert effort into many different activities. This multi-project environment, in practice, frequently induces a set of disagreements among the principals when they compete against each other for receiving the agent's effort [2-5]. As a consequence, the built-in propensities to conflict within the matrix structure substantially limit its effectiveness. The below example of Asea Brown Boveri (ABB) is typical, given that the inherent propensity for conflict among principals often exists within a matrix organization [6].

"The new structure will allow us to serve our customers better, enhance the external focus and more closely integrate our senior managers in local markets into our global management teams."

Jurgen Dormann, CEO, ABB Group, 2002. 
The matrix organizational structure implemented by $A B B$ served as a model for organizations with operations all over the world... However, notwithstanding its definite advantages, the matrix structure led to a few problems for ABB. Conflict of interests between the business are that management and the regional management often resulted in delayed decision making ... This, in turn, affected $A B B^{\prime}$ 's ability to respond quickly to the rapidly changing business environment.

However, notice that the conflict among principals does not necessarily bring about less than optimum performance. While all principals may not achieve full agreement, it is still possible that many conflicts can be resolved by various ways: such as compromise, accommodation, avoidance, collaboration, or the use of explanations/social accounts. Clearly, this implies that the critical problems do arise when the conflict among principals inevitably generates an efficiency loss within the matrix organization. Among the possible factors, we propose that an asymmetry of information among principals can be the primary source. Accordingly, this paper theoretically examines whether the asymmetric information among principals causes the inherent propensity for conflict to unavoidably reduce the effectiveness of matrix organization.

Specifically, our research objective is two-fold. First, to focus on the asymmetric information between the two principals, we examine how the asymmetric information affects the agent's incentives to provide an effort. Second, we expand the first research question by supposing that the relative weight of the agent's profit set to each principal varies.

We address these issues by analyzing how the asymmetric information among the principals affects the agent's incentives to provide an effort. Our analysis is developed in a situation in which the two non-identical principals and a common agent co-exist in a matrix organization. Each principal undertakes only one project into which the agent must exert his effort. We deem those projects to be completely different from one another, implying that the agent has to provide his effort separately for each project. Additionally, we assume that while one of the two principals has substantial amount of information about her project, the other principal has no information about her project. Based on this assumption, we define the asymmetry of information between the two principals as each principal having a different amount of information regarding their project. In this paper, we refer to a principal who is considerably informed about her project as the well informed (WI) principal, and a principal who is not informed about her project as the poorly informed (PI) principal. Since these principals both have an authority (or power) to give the agent an order, it naturally follows that the asymmetric information between the two principals would affect the agent's incentives to provide an effort.

In the first part of the paper, to focus on the asymmetric information between the two principals, we examine how the asymmetric information affects the agent's incentives to provide an effort, given that each principal has an equal authority. Notice that the agent, bent on maximizing his utility, will consider not only the asymmetric information between the two principals, but also the relative extent of authority retained by the two principals. Thus, it is reasonable to posit that if the relative authority of each principal is taken to be equivalent, the main factor which predominantly drives the agent's behavior would be the asymmetric information between the two principals.

Within this setting, we demonstrate that while the agent exerts the maximum amount of his effort for the PI principal, the agent does not make the maximum amount of effort for the WI principal. Interestingly, this result establishes a meaningful resource allocation implication within the organization. In multi-project environments, an efficient allocation of resources is viewed as the major concern because it determines the achievement of the overall organizational goals. So, when it comes to maintaining an efficient flow of resources among the various projects, it is definite that the available resources, i.e., the agent's effort, must be intensively allocated to the principal who has relatively higher ability to perform the project. Our finding, however, shows that the resources rather flow into the principal who has relatively lower ability to perform the project.

In the second part of the paper, we expand the first part by supposing that the relative weight of the agent's profit set to each principal varies. Note that the question of how the asymmetric information between the two principals affects the agent's incentives to provide an effort relies heavily on the 
premise that both the principals have an authority to direct the agent. This implies that if the relative weight conferred to each principal varies, the influence of each principal on the agent's behavior also varies. Thus, this change in relative weight of an agent's profit when combined with the asymmetric information between the two principals ultimately affects the agent's incentives to provide an effort: That is, there exists an interactive effect between the relative weight and the asymmetric information.

In this part, we first analyze how the interactive effects between the relative weight of the agent's profit and the asymmetric information influence the agent's incentives to provide an effort. Similar to the observations in the first part of the paper, we show that although the agent provides the maximum amount of effort to the PI principal, the agent does not put the maximum amount of effort for the WI principal. This, again, suggests that the inefficient allocations of resources prevail in the organization. More surprisingly, however, we identify that when the relative weight of the agent's profit set to the WI principal increases, the efficiency loss in allocating the resources between the two principals decreases. This finding clearly supports our argument that the inefficient resource allocation problem is generated by the interactive effects between the relative weight and the asymmetric information, not merely by the asymmetric information.

Next, in order to give an in-depth understanding of the interactive effects between the relative weight and the asymmetric information, we finally examine how this interactive affects impact on the overall performance of the organization. Our results show that unless the WI principal solely determines the agent's profit, the total wealth of the organization is always not optimal. This finding demonstrates that the exact source which inevitably threatens the overall success of the organization is that the PI principal has the authority to give the agent an order. Our final analysis, thus, confirms the preceding argument that the inefficient allocation of resources which eventually limits the overall performance of the organization is affected by the interactive effects, rather than by the asymmetric information alone.

There are many prior literatures related to this paper. First, the present paper is closely linked to the strand of literatures which focuses on the organization design [7-12]. An interesting subject in this area, relatively underexplored in the economics literature, is to evaluate the determinants of the organization's choice among the various structures [13]. Several researchers have asserted that the trade-off between the benefit of coordinating different functions and the cost of losing the economies of scale mainly drives the choice between divisional and functional structures. Furthermore, Harris and Raviv [13] demonstrate that the choice between hierarchical and matrix structures is determined by the relative importance of coordinating various activities and reducing the cost of using managers' time. Our study adds to this line of researches, arguing that the interactive effects between the relative weight of the agent's profit and the asymmetric information which inevitably reduces the effectiveness of the matrix organization can be the primary determinant in choosing the organization structure.

Second, this paper is also related to the agency literatures [14-26]. Agency literatures in economics generally assume hierarchical structure where a subordinate reports to only one superior and thus have largely ignored the common agency element. Moreover, by and large, with the exception of papers by Aghion and Tirole [27], Baker et al. [28], and Rajan and Zingales [29], the existing literature does not analyze the principal-agent relationship in terms of authority. In contrast, this paper not only introduces a multi-principal or common agency approach, but also focuses on the relative weight of the agent's profit retained by multiple principals. By doing so, we show that the interactive effects between the relative weight and asymmetric information do influence the common agent's incentives to provide an effort. This result is, to the best of our knowledge, new and may offer an additional insight to the agency literatures.

This paper proceeds as follows. Section 2 presents a description of the model and discusses how the asymmetric information between the two principals affects the agent's incentives to provide an effort. Section 3 characterizes the interactive effects between relative weight and asymmetric information. Section 4 concludes and suggests avenues of future research. 


\section{The Model}

In this paper, we consider a matrix organization that is composed of two non-identical principals (i.e., two project managers) and one agent (i.e., a lower level manager). This agent is regarded as the common agent. Each principal has only one project which is different from one another. A key assumption in our model is that there are two principals who are discriminated only by the differences of the amount of information each principal has with respect to their preferred investment project. For the sake of brevity, we set one of the two principals having perfect information about her project while the other principal having no information about her project.

In this paper, we presume that the amount of information each principal has regarding the other principal's investment project does not matter. That is, we only consider the amount of information each principal has about her preferred investment project. Additionally, all of the results in this paper are true for any arbitrary forms of different amounts of information that distinguish the two principals.

Since the two projects are started concurrently, the agent has two tasks (two projects) on which he should work and generates the effort separately to each principal. We assume that the agent does not provide an effort which simultaneously affects both principals. In addition, we assume that the agent has perfect knowledge about both projects. This induces the principals to work closely with the agent for the purpose of completing their project successfully, given that both principals have an authority (or power) to give the agent an order.

\subsection{Unique Properties of the Two Principals}

In order to start our analysis, we first need to define the unique properties of two non-identical principals formally. In this subsection, we present two kinds of willingness-to-pay functions from which the unique characteristics of the two principals are derived.

Maximum willingness-to-pay function: The principal i's total utility is given by $u_{i}\left(e_{i}\right)+y_{i},=1$, 2 , where $e_{i}$ is the amount of agent's effort for the principal $i$ and $y_{i}$ is the performance of principal i's project. Maximum willingness-to-pay function: The principal i's total utility is given by $u_{i}\left(e_{i}\right)+y_{i}, i$ $=1,2$, where $e_{i}$ is the amount of agent's effort for the principal $i$ and $y_{i}$ is the performance of principal i's project. As shown, we define the total utility of each principal as the sum of the utility generated from the agent's effort (i.e., $u_{i}\left(e_{i}\right)$ ) and the performance of the project (i.e., $\left.y_{i}\right)$. To make it clear, we specify that the utility (not total utility) refers to the benefits that are solely derived from the agent's effort itself. Additionally, $\mathrm{u}(\bullet)$ is a non-negative, twice differentiable, and strictly concave function. We assume that $y_{i}$ increases as the agent puts more effort to the principal i's project. In addition, if the agent exerts the maximum effort into the principal i's project, $\mathrm{y}_{\mathrm{i}}$ is optimized. To make the principal i's total utility simple, we normalize the optimum value of $y_{i}$ to 1 . Therefore, $0 \leq y_{i} \leq 1$.

Throughout this paper, $y_{i}$ belongs only to the principal $i$, and the maximum payment which each principal is willing to compensate for the agent's individual effort is based on the level of her utility, i.e., $u_{i}\left(e_{i}\right)$. Thus, when the principal i's maximum willingness-to-pay for the agent's effort is denoted by $t_{i}\left(e_{i}\right)$, it is the solution to the Equation (1):

$$
u_{i}(0)=u_{i}\left(e_{i}\right)-t_{i}\left(e_{i}\right) .
$$

If we set $u_{i}(0)=0$, the maximum willingness-to-pay function for the principal $i$ turns out to be:

$$
t_{i}\left(e_{i}\right) \equiv u_{i}\left(e_{i}\right)
$$

Marginal willingness-to-pay function: In addition to the maximum willingness-to-pay function, we need to consider another useful function which is associated with the principal's utility. The function we have in mind is the marginal willingness-to-pay function of each principal which is denoted as $\mathrm{v}_{\mathrm{i}}\left(\mathrm{e}_{\mathrm{i}}\right)$ and is given by:

$$
\mathrm{v}_{\mathrm{i}}\left(\mathrm{e}_{\mathrm{i}}\right)=\mathrm{u}_{\mathrm{i}}^{\prime}\left(\mathrm{e}_{\mathrm{i}}\right) \text {. }
$$


Equation (3) expresses the marginal willingness-to-pay function of each principal. We observe that this function determines the set of the amount of an agent's individual effort and the principal i's marginal payment for the agent's marginal effort. Notice that a rational principal, by definition, will compensate for the agent's effort in accordance with her marginal willingness-to-pay function.

Unique properties of the two principals: With these two types of willingness-to-pay functions complete, we now define the unique properties of the two principals. As we mentioned above, the two non-identical principals are distinguished only by the amount of information with respect to their project. Intuitively, this asymmetry of information causes each principal to have different values regarding the agent's effort. That is, we argue that the two principals, due to dissimilar amount of information about their own project, might place distinct values upon the agent's effort. This argument is well represented by the two definitions stated below.

Definition 1. Given the amount of agent's effort (e), the maximum willingness-to-pay by the principal 2 always exceeds the maximum willingness-to-pay by the principal 1 ; i.e., that

$$
\mathrm{u}_{2}(\mathrm{e})>\mathrm{u}_{1}(\mathrm{e}) \text { for all e. }
$$

Definition 2. Given the amount of agent's effort (e), the marginal willingness-to-pay by the principal 2 always exceeds the marginal willingness-to-pay by the principal 1; i.e., that

$$
u_{2}^{\prime}(e)>u^{\prime}{ }_{1}(e) \text { for all e. }
$$

Definitions 1 and 2 are based on the maximum and marginal willingness-to-pay functions of each principal, showing that each principal's placed value on the agent's total and marginal effort is different from one another. As a result, these definitions reflect the asymmetric information between the two principals appropriately.

\subsection{The Profit Function of The Common Agent}

Following the prior subsection, we next consider the profit function of the common agent before we begin our analysis. We (plausibly) assume that the agent is able to distinguish the two principals from each other. Naturally, this implies that the agent knows the marginal willingness-to-pay functions of both principals. The marginal willingness-to-pay function of the individual principal is denoted by $v_{i}\left(e_{i}\right)$, for $\mathrm{i}=$ principal 1,2 .

Moreover, the agent knows that if he provides an effort for the principal $i$, the principal i pays the amount which is equal to $s_{i}=v_{i}\left(e_{i}\right) e_{i}$. In order to make this statement clear, we need the following two assumptions. First, both principals are able to make inferences about the level of efforts which the agent has generated for their respective investment projects. This assumption is reasonable since both principals could make a judgment about the agent's effort through the process such as the regular reports of the agent. To illustrate, suppose that we have two CEOs (principals) and one middle manager (agent). The middle manager, in practice, reports to each principal on a regular basis regarding the relevant issues of investment project. This procedure induces both principals to make an appropriate judgment about the agent's effort. Second, the effort which is provided by the agent to the principal i should be the same as the effort which is inferred by the principal i. As long as the process which each principal counts on to infer the agent's effort is reliable, this assumption is naturally satisfied.

We now consider the two sets of constraints which the agent faces. The first set of constraints is given by:

$$
\mathrm{u}_{1}\left(\mathrm{e}_{1}\right)-\mathrm{s}_{1} \geq 0
$$

and

$$
\mathrm{u}_{2}\left(\mathrm{e}_{2}\right)-\mathrm{s}_{2} \geq 0 \text {. }
$$


These constraints simply show that each principal pays the agent an amount which does not exceed each principal's utility generated from receiving the agent's effort. Thus, the first set of constraints, i.e., Equations (6) and (7), are called participation constraints.

The second set of constraints is given by:

$$
\mathrm{u}_{1}\left(\mathrm{e}_{1}\right)-\mathrm{s}_{1} \geq \mathrm{u}_{1}\left(\mathrm{e}_{2}\right)-\mathrm{s}_{2}
$$

and

$$
\mathrm{u}_{2}\left(\mathrm{e}_{2}\right)-\mathrm{s}_{2} \geq \mathrm{u}_{2}\left(\mathrm{e}_{1}\right)-\mathrm{s}_{1} .
$$

The second set of constraints, i.e., Equations (8) and (9), suggests that each principal must prefer the amount of effort which is intended by the agent to provide for her rather than the amount of effort that is intended by the agent to provide for the other principal. As noted in the prior subsection, the principal 2 when compared to principal 1 sets a relatively high value on the agent's effort. Since the agent is able to distinguish the principal 2 from the principal 1, it is evident that the agent might provide a larger amount of effort for the principal 2. Notice that these different amounts of the agent's effort for each principal reflect each principal's dissimilar preferences for the agent's effort. As a consequence, the principal must prefer the amount of agent's effort which is intended by the agent to provide for her. This reasoning justifies our second set of constraints and thus we call these constraints as self-selection constraints.

Now, based on these two sets of constraints, we derive the profit function of the common agent. We begin by rearranging the inequalities of Equations (6)-(9) as:

$$
\begin{gathered}
\mathrm{s}_{1} \leq \mathrm{u}_{1}\left(\mathrm{e}_{1}\right), \\
\mathrm{s}_{1} \leq \mathrm{u}_{1}\left(\mathrm{e}_{1}\right)-\mathrm{u}_{1}\left(\mathrm{e}_{2}\right)+\mathrm{s}_{2}, \\
\mathrm{~s}_{2} \leq \mathrm{u}_{2}\left(\mathrm{e}_{2}\right),
\end{gathered}
$$

and

$$
\mathrm{s}_{2} \leq \mathrm{u}_{2}\left(\mathrm{e}_{2}\right)-\mathrm{u}_{2}\left(\mathrm{e}_{1}\right)+\mathrm{s}_{1} .
$$

According to the binding rule, it generally follows that one of the first two inequalities will be binding and one of the second two inequalities will be binding. It turns out that DEFINITION 1 and 2 are sufficient to determine which constraints will bind, as we now demonstrate.

Consider the inequalities of Equations (12) and (13) first. When we assume that Equation (12) is binding, then Equation (13) suggests that:

$$
\mathrm{s}_{2} \leq \mathrm{s}_{2}-\mathrm{u}_{2}\left(\mathrm{e}_{1}\right)+\mathrm{s}_{1}
$$

or

$$
\mathrm{u}_{2}\left(\mathrm{e}_{1}\right) \leq \mathrm{s}_{1} .
$$

Using Equation (4), i.e., DEFINITION 1, we can write:

$$
\mathrm{u}_{1}\left(\mathrm{e}_{1}\right)<\mathrm{u}_{2}\left(\mathrm{e}_{1}\right) \leq \mathrm{s}_{1}
$$

which violates Equation (10). As a result, it becomes evident that Equation (12) is not binding and that Equation (13) is binding.

We note this result for future use as:

$$
\mathrm{s}_{2}=\mathrm{u}_{2}\left(\mathrm{e}_{2}\right)-\mathrm{u}_{2}\left(\mathrm{e}_{1}\right)+\mathrm{s}_{1} .
$$


Subsequently, we need to consider the inequalities of Equations (10) and (11). When we assume that Equation (11) is binding, we would have:

$$
\mathrm{s}_{1}=\mathrm{u}_{1}\left(\mathrm{e}_{1}\right)-\mathrm{u}_{1}\left(\mathrm{e}_{2}\right)+\mathrm{s}_{2} .
$$

If we substitute $s_{2}$ with Equation (16), then:

$$
\mathrm{s}_{1}=\mathrm{u}_{1}\left(\mathrm{e}_{1}\right)-\mathrm{u}_{1}\left(\mathrm{e}_{2}\right)+\mathrm{u}_{2}\left(\mathrm{e}_{2}\right)-\mathrm{u}_{2}\left(\mathrm{e}_{1}\right)+\mathrm{s}_{1} .
$$

This implies that:

$$
\mathrm{u}_{2}\left(\mathrm{e}_{2}\right)-\mathrm{u}_{2}\left(\mathrm{e}_{1}\right)=\mathrm{u}_{1}\left(\mathrm{e}_{2}\right)-\mathrm{u}_{1}\left(\mathrm{e}_{1}\right) .
$$

We are able to rearrange this expression as

$$
\int_{e_{1}}^{e_{2}} u_{1}^{\prime}(t) d t=\int_{e_{1}}^{e_{2}} u_{2}^{\prime}(t) d t
$$

However, since this expression contradicts DEFINITION 2, it naturally follows that (11) is not binding and that (10) is binding. Therefore:

$$
\mathrm{s}_{1}=\mathrm{u}_{1}\left(\mathrm{e}_{1}\right)
$$

Note that the marginal cost of the agent's effort is assumed to be constant and denoted by $\mathrm{m}$. Then, as $\left(s_{1}-m_{1}\right)$ and $\left(s_{2}-m_{2}\right)$ indicates the agent's profit that is generated from providing the effort for the principal 1 and 2, respectively, we need to consider the profit function of the agent that is given by:

$$
\Pi=\left(\mathrm{s}_{1}-\mathrm{me}_{1}\right)+\left(\mathrm{s}_{2}-\mathrm{me}_{2}\right) .
$$

If we substitute $s_{1}$ and $s_{2}$ using Equation (19) and Equation (16), respectively, the agent's profit function modifies to:

$$
\Pi=\left[\mathrm{u}_{1}\left(\mathrm{e}_{1}\right)-\mathrm{me}_{1}\right]+\left[\mathrm{u}_{2}\left(\mathrm{e}_{2}\right)-\mathrm{u}_{2}\left(\mathrm{e}_{1}\right)+\mathrm{u}_{1}\left(\mathrm{e}_{1}\right)-\mathrm{me}_{2}\right] .
$$

For the rest of the paper, we formally use Equation (21) as the profit function of the common agent.

\subsection{Asymmetric Information and Agent's Incentives}

Now, we proceed to the analysis. As noted in the Introduction, we first examine how the asymmetric information between the two principals affects the agent's incentives to provide an effort. The analysis focuses on a situation in which one of the two principals has the full amount of information about her project while the other principal has no information about her project.

Notice that the profit function of the agent is obtained by using the two sets of constraints: participation constraints and self-selection constraints. Among those, the self-selection constraints rely heavily on the circumstance where each principal is characterized by their amount of information about the project. Moreover, as we have discussed in the text, DEFINITION 1 and 2 which primarily reflect the asymmetry of information between the two principals, play an important role while we derive our profit function of the agent. That is, the profit function itself is closely connected with the information asymmetry implying that the agent, for the purpose of maximizing his self-interest, will concentrate mainly on the asymmetric information between the two principals. Therefore, we strongly conjecture that the crucial determinant which affects the agent's incentives to provide an effort might be the asymmetric information discriminating the two principals. 
In order to examine how the asymmetry of information affects the agent's incentives, we need to solve the maximization problem of the agent's profit function. The profit function of the agent is given by:

$$
\Pi=\left[\mathrm{u}_{1}\left(\mathrm{e}_{1}\right)-\mathrm{me}_{1}\right]+\left[\mathrm{u}_{2}\left(\mathrm{e}_{2}\right)-\mathrm{u}_{2}\left(\mathrm{e}_{1}\right)+\mathrm{u}_{1}\left(\mathrm{e}_{1}\right)-\mathrm{me}_{2}\right] .
$$

Differentiating the Equation (21) with respect to e1 and e2, we have the following first-order conditions that are given by:

$$
\mathrm{u}^{\prime}{ }_{1}\left(\mathrm{e}_{1}^{*}\right)-\mathrm{m}+\mathrm{u}^{\prime}{ }_{1}\left(\mathrm{e}_{1}^{*}\right)-\mathrm{u}_{2}^{\prime}\left(\mathrm{e}_{1}^{*}\right)=0
$$

and

$$
\mathrm{u}_{2}^{\prime}\left(\mathrm{e}_{2}^{*}\right)-\mathrm{m}=0
$$

According to DEFINITION 2, $\mathrm{u}^{\prime}{ }_{2}\left(\mathrm{e}_{1}{ }^{*}\right)-\mathrm{u}^{\prime}{ }_{1}\left(\mathrm{e}_{1}{ }^{*}\right)$ is always positive. Thus, we can rewrite the Equation (22) as:

$$
\mathrm{u}^{\prime}{ }_{1}\left(\mathrm{e}_{1}^{*}\right)=\mathrm{m}+\left[\mathrm{u}_{2}{ }_{2}\left(\mathrm{e}_{1}^{*}\right)-\mathrm{u}_{1}^{\prime}\left(\mathrm{e}_{1}{ }^{*}\right)\right]>\mathrm{m} .
$$

As shown, Equations (23) and (24) imply the agent's respective effort for the principal 2 and 1 , respectively.

From Equation (23), we first observe that the agent's marginal effort is compensated by the principal 2's marginal payment which is equal to the marginal cost of the agent's effort. When it comes to our definition of the marginal willingness-to-pay function, the principal's marginal payment decreases as the agent provides more effort for her. Consequently, if the agent provides an amount of effort which is greater than $\mathrm{e}_{2}{ }^{*}$, the principal 2's marginal payment for the agent's marginal effort becomes lower than the marginal cost of the agent's effort. Since a rational agent would not behave like this, we conclude that $\mathrm{e}_{2}{ }^{*}$ is the maximum amount of the agent's effort that he can afford to provide for the principal 2.

Next, we consider the case of the agent's effort for the principal 1. Equation (24) shows that the agent's marginal effort is compensated by the principal 1's marginal payment which is higher than the marginal cost of the agent's effort. In contrast to $\mathrm{e}_{2}{ }^{*}$, this result suggests that the agent does not make a maximum amount of effort into the principal 1's project.

As is well known, these observations are developed in a setting where principal 1 and 2 are characterized primarily by their asymmetry of information with respect to their individual project. Additionally, this characteristic is represented properly by DEFINITION 1 and 2, i.e., $\mathrm{u}_{2}(\mathrm{e})>\mathrm{u}_{1}(\mathrm{e})$ and $\mathrm{u}_{2}{ }_{2}(\mathrm{e})>\mathrm{u}_{1}{ }_{1}(\mathrm{e})$ for all e, respectively. Notice that these definitions provide an important basis when we determine which principal (that is, principal 1 or 2) is likely to be designated as having perfect knowledge (or no information) about her project. Specifically, consider the extreme case in which the agent does not help the two principals (that is, the agent does not exert an effort to either project). In this situation, the principal who has no information might inevitably fail to accomplish her project. On the contrary, the other principal could at least progress the project by herself since she has perfect knowledge about her own project. It is therefore reasonable to believe that the one having no (full) information about her individual project could be set to the principal 2 (principal 1) who places relatively higher (lower) value on the agent's effort. For the remainder of the paper, we refer to principal 2 as poorly informed (PI) principal and principal 1 as well informed (WI) principal.

We summarize this discussion in the following theorem.

Theorem 1. Suppose the asymmetric information between the PI principal and WI principal exists, i.e., we define that $u_{P}(e)>u_{W}(e)$ and $u_{P}^{\prime}(e)>u^{\prime}{ }_{W}(e)$ for all e, where $p$ and $w$ denote PI and WI principal, respectively.

(a) The agent provides the maximum amount of effort for the PI principal. Thus, $e_{P}{ }^{*}$ is optimal for the PI principal.

(b) The agent does not provide the maximum amount of effort for the WI principal. Thus, $e_{W}{ }^{*}$ is not optimal for the WI principal. 
Theorem 1 demonstrates how the asymmetric information between the two principals would influence the agent's incentives to provide an effort. Notice that this theorem provides an important implication for maintaining an efficient allocation of human resources in multi-project environments. Intuitively, in order to enhance the overall success of the organization, it is desirable to concentrate the valuable resources on the person who has the superior ability to perform the task. However, our findings suggest that an important resource, i.e., the amount of the agent's effort, rather flows into the person who has the inferior ability to perform the task. As a result, we conclude that the asymmetric information between the two principals might be the key source which substantially limits the effectiveness of the organization.

\section{Interactive Effects between Relative Weight and Asymmetric Information}

The question of how the asymmetric information between the two principals affects the agent's incentives to provide an effort relies heavily on the premise that both the principals are able to have an effect on the agent's profit. In addition, this premise suggests that, if the relative weight of the agent's profit set to each principal varies, then the influence of each principal on the agent's behavior also varies, given that the amount of agent's effort for the principals is fixed. Thus, this change in relative weight when combined with the asymmetric information between the two principals might ultimately affect the agent's incentives to provide an effort: That is, there exists an interactive effect between the relative weight and the asymmetric information. To explore the interactive effects, we expand the model by explicitly introducing the relative weight of the agent's profit set to each principal. More specifically, allowing the relative weight to vary, we examine how the interactive effects between the relative weight and the asymmetric information impact the agent's incentives to provide an effort.

As we have already denoted principal 1 and 2 by WI and PI principal, respectively, the profit function of the agent in the previous section, i.e., Equation (21), is rewritten as:

$$
\Pi=\left[u_{W}\left(e_{W}\right)-m_{W}\right]+\left[u_{P}\left(e_{P}\right)-u_{P}\left(e_{W}\right)+u_{W}\left(e_{W}\right)-m e_{P}\right] .
$$

Since $\left[u_{W}\left(e_{W}\right)-m_{W}\right]$ indicates the portion of the agent's profit that is compensated by the WI principal, we let $\alpha$ denote the relative weight of the agent's profit set to WI principal. Additionally, since $\left[u_{P}\left(e_{P}\right)-u_{P}\left(e_{W}\right)+u_{W}\left(e_{W}\right)-m_{P}\right]$ shows the share of the agent's profit paid by the PI principal, we let $(1-\alpha)$ denote the relative weight of the agent's profit set to PI principal. Therefore, Equation (25) is modified to:

$$
\Pi=\alpha\left[u_{W}\left(e_{W}\right)-e_{W}\right]+(1-\alpha)\left[u_{P}\left(e_{P}\right)-u_{P}\left(e_{W}\right)+u_{W}\left(e_{W}\right)-m e_{P}\right],
$$

where $0<\alpha<1$.

Now, to examine how the interactive effects might influence the agent's incentives, this expression is to be maximized with respect to $\mathrm{e}_{\mathrm{W}}$ and $\mathrm{e}_{\mathrm{P}}$. Differentiating, we get the following first order conditions that are given by:

$$
\alpha\left[u^{\prime}{ }_{W}\left(e_{W}^{*}\right)-m\right]+(1-\alpha)\left[u^{\prime}{ }_{W}\left(e_{W}{ }^{*}\right)-u^{\prime}{ }_{P}\left(e_{W}{ }^{*}\right)\right]=0
$$

and

$$
\mathrm{u}_{\mathrm{P}}^{\prime}\left(\mathrm{e}_{\mathrm{P}}^{*}\right)-\mathrm{m}=0 .
$$

If we consider the proof of Theorem 2(bi) in the Appendix A, Equation (27) can be rearranged to give:

$$
\mathrm{u}^{\prime}{ }_{\mathrm{W}}\left(\mathrm{e}_{\mathrm{W}}{ }^{*}\right)=\alpha \mathrm{m}+\left[\mathrm{u}_{\mathrm{P}}^{\prime}\left(\mathrm{e}_{\mathrm{W}}^{*}\right)-\alpha \mathrm{u}_{\mathrm{P}}{ }\left(\mathrm{e}_{\mathrm{W}}{ }^{*}\right)\right]>\mathrm{m} .
$$

By taking the interactive effects between the relative weight and the asymmetric information into account, the agent's individual effort for the PI and WI principal is shown in Equation (28) and Equation (29), respectively. 
First, we consider the agent's effort for the PI principal. From Equation (28), we find that the PI principal's marginal payment for the agent's marginal effort equals the marginal cost of the agent's effort. Surprisingly, this result indicates that the agent always puts a maximum amount of effort for the PI principal, irrespective of the relative weight of the agent's profit set to each principal. That is, unless the PI principal has no effect on the agent's profit, the agent exerts the greatest effort into the PI principal's project for the purpose of maximizing his wealth.

Next, Equation (29) shows the agent's effort for the WI principal. As we observe, the WI principal's marginal payment for the agent's marginal effort is higher than the marginal cost of the agent's effort. Thus, same as in the prior section, the agent still does not provide a maximum amount of effort for the WI principal. However, it should be noted that the agent's effort for the WI principal is affected by the relative weight between the two principals. To explore this issue, a further examination of Equation (29) is needed.

If we differentiate the right hand side of Equation (29) with respect to $\alpha$, we get (see the proof of Theorem 2(bi) in the Appendix A):

$$
\mathrm{m}-\mathrm{u}_{\mathrm{P}}^{\prime}\left(\mathrm{e}_{\mathrm{W}}^{*}\right)<0 .
$$

Equation (30) shows that the WI principal's marginal payment decreases as the relative weight of the agent's profit set to the WI principal increases. Naturally, this also implies that the agent gradually provides more amount of his effort for the WI principal. Intuitively, this result follows because, when the agent's profit is largely determined by the WI principal, the agent has to increase his effort for the WI principal in order to maximize the profit.

We summarize this discussion in the following theorem.

Theorem 2. Suppose that the interactive effects between the relative weight and the asymmetric information exist.

(a) The agent provides the maximum amount of effort for the PI principal. Thus, $e_{P}{ }^{*}$ is optimal for the PI principal.

(bi) The agent does not provide the maximum amount of effort for the WI principal. Thus, $e_{W}{ }^{*}$ is not optimal for the WI principal.

(bii) When the relative weight of the WI principal, i.e., $\alpha$, increases, $e_{W}{ }^{*}$ also increases.

Theorem (bi) and (bii) identifies that as long as Theorem (a) holds (and notice that it is always the case), the efficiency loss in allocating the resources within the organization becomes less as the relative weight of the agent's profit set to the WI principal increases. This demonstrates that the inefficient allocation of resources between the two principals is virtually induced by the interactive effects between the distribution of the relative weight and the asymmetric information rather than by the asymmetric information between the principals alone. However, it should be noted that Theorem 2 , as a whole, highlights the more important implication. Even if the inefficient resource allocation problem lessens by setting the relative weight of the WI principal higher, the problem still exists in an organization. As a consequence, we conclude that the role of the relative weight in successfully diminishing the inefficient allocation of resources which is induced by the information asymmetry between the two principals is limited.

Finally, to provide a thorough understanding of the interactive effects between the relative weight and the asymmetric information, we further investigate the impact of these joint effects on the overall success of the organization. In order to address this issue, we examine how the interactive effects influence the total wealth created by the two principals and one agent.

The individual wealth created by the WI principal, PI principal, and the agent are given by:

$$
\begin{gathered}
\mathrm{W}_{\mathrm{W}}=\mathrm{u}_{\mathrm{W}}\left(\mathrm{e}_{\mathrm{W}}^{*}\right)+\mathrm{y}_{\mathrm{W}}-\mathrm{s}_{\mathrm{W}}, \\
\mathrm{W}_{\mathrm{P}}=\mathrm{u}_{\mathrm{P}}\left(\mathrm{e}_{\mathrm{P}}^{*}\right)+\mathrm{y}_{\mathrm{P}}-\mathrm{s}_{\mathrm{P}},
\end{gathered}
$$


and

$$
\Pi=\alpha\left[u_{W}\left(e_{W^{*}}^{*}\right)-m_{W^{*}}^{*}\right]+(1-\alpha)\left[u_{P}\left(e_{P}^{*}\right)-u_{P}\left(e_{W}^{*}\right)+u_{W}\left(e_{W}^{*}\right)-m_{P}^{*}\right],
$$

respectively.

By adding up the $W_{W}, W_{P}$, and $\Pi$, the total wealth created by the two principals and one agent is derived by:

$$
\mathrm{W}_{\mathrm{T}}=\alpha\left[\mathrm{u}_{\mathrm{W}}\left(\mathrm{e}_{\mathrm{W}}^{*}\right)-\mathrm{me}_{\mathrm{W}}{ }^{*}\right]+\left[\mathrm{y}_{\mathrm{W}}+\mathrm{y}_{\mathrm{P}}\right] .
$$

In this paper, we (plausibly) assume that when the agent exerts the maximum amount of effort into the WI (PI) principal's project, $\mathrm{yw}_{\mathrm{W}}\left(\mathrm{y}_{\mathrm{P}}\right)$ is optimized. The agent, as we observe from Equation (28), always puts a maximum amount of effort for the PI principal's project, regardless of the relative weight of his profit set to each principal. Thus, $\mathrm{y}_{\mathrm{P}}$ is always equal to 1 . Next, consider the performance of the WI principal's project, i.e., $\mathrm{y}_{\mathrm{W}}$. From Equation (30), we find that as $\alpha$ increases, the agent exerts more amount of his effort for the WI principal's project. This, by definition, indicates that $\mathrm{y}_{\mathrm{W}}$ also increases when the relative weight of the WI principal increases.

Lastly, we look into the remaining terms, i.e., $\alpha\left[u_{W}\left(e_{W}^{*}\right)-m_{W^{*}}\right]$, at the right hand side of the Equation (34). An examination of these terms shows two conditions that (1) $u_{W}\left(e_{W^{*}}\right)-m_{W}{ }^{*}$ is always positive, and (2) when $\mathrm{e}_{\mathrm{W}}{ }^{*}$ increases, $\mathrm{u}_{\mathrm{W}}\left(\mathrm{e}_{\mathrm{W}}{ }^{*}\right)-\mathrm{me}_{\mathrm{W}}{ }^{*}$ also increases. These two conditions, coupled with our finding that $\mathrm{e}_{\mathrm{W}^{*}}$ increases when $\alpha$ increases, enable us to establish that as $\alpha$ increases, the positive value of $u_{W}\left(e_{W^{*}}^{*}\right)-m_{W^{*}}$ increases also. That is to say, we observe that $\alpha\left[u_{W}\left(e_{W}{ }^{*}\right)-m_{W^{*}}\right]$ increases as the relative weight of the WI principal increases.

Collectively, these observations demonstrate that the total wealth generated by the two principals and one agent, i.e., $\mathrm{W}_{\mathrm{T}}$, increases as the relative weight set to the WI principal, i.e., $\alpha$, increases. Notice that, however, as long as the WI principal does not solely determine the agent's profit, i.e., $\alpha<1$, the total wealth produced by the two principals and one agent is always less than the optimum value. This is obvious because no matter how high the relative weight of the WI principal is, it is still possible that the total wealth can increase as the relative weight of the WI principal marginally increases.

We summarize this discussion in the following theorem.

Theorem 3. Suppose that the interactive effects between the relative weight and the asymmetric information exist.

(a) As the relative weight of the WI principal marginally increases, the total wealth created by the WI principal, PI principal, and the agent also marginally increases.

(b) Unless the WI principal influences singly the agent's profit, i.e., $\alpha<1$, the total wealth is not optimal.

Theorem 3(b) identifies that the exact source which inevitably undermines the overall performance of the organization is that the PI principal can influence the agent's behavior by affecting his profit. This is intuitive. The PI principal, due to the inability to properly do her work, would not go toward generating an additional wealth for the organization. Notwithstanding this fact, making the PI principal to receive the valuable resources, i.e., the agent's effort, naturally limits the efficient flow of resources within the organization. Moreover, Theorem 3(a) corroborates Theorem 3(b) by showing that when the relative weight set to PI principal becomes greater compared to the WI principal, the overall performance of the organization exacerbates more. Theorem 3 taken as a whole, thus, confirms our primary argument that the information asymmetry between the two principals might be the crucial factor which impairs the efficient allocation of resources in the matrix organization.

Meanwhile, one might expect that this inefficiency can be resolved by several ways. For instance, the two principals can set a contract on the condition that in exchange for the WI principal having all the weight of the agent's profit, the WI principal would give some portion of her share to the PI principal. Additionally, if such a contract is not possible, the WI principal, by raising an objection to the delegation process of the principals, may have the PI principal necessarily replaced to the other one. Note that, however, this can happen only when the two principals know perfectly about how much information the other principal has with respect to her project. Even though it may be true for few 
cases, in a general context it is more reasonable to assume that this can hardly hold. As a consequence, we conclude that under the circumstances where the PI principal remains, the inefficient resource allocation problem within the organization is inevitable.

\section{Conclusions}

In this paper, we theoretically examine the effect of information asymmetry between the two principals on the common agent's incentives to provide an effort. The analysis focuses on the circumstances where the two principals are discriminated only by the different amount of information regarding her own project. We demonstrate that while the agent puts on optimal amount of effort for the PI principal, she does not provide an optimal level of effort for the WI principal. Intuitively, it is reasonable to argue that the available resources within the organization, i.e., the agent's effort, must be allocated to the person whose ability is high. However, our finding suggests that the valuable resource, i.e., the agent's effort, rather flows into the person whose ability is relatively low, implying that the asymmetric information between the two principals is the primary source of inefficiency within the organization.

In addition, we investigate whether this inefficiency is attenuated by changes of the relative weight of the agent's profit set to each principal. We show that as long as the PI determines the part of the agent's total profit, the efficiency loss within the organization still remains. Similarly, our final analysis suggests that unless the WI principal alone influences the agent's profit, the total wealth created by the two principals and common agent is always less than optimal level. Taken together, these findings corroborate our primary assertion that so long as the PI principal exists within the organization, the inefficiency might be inevitable.

Based on these findings, this study is expected to provide differentiated results compared to previous studies regarding the principal-agent relationship and organizational structure. In addition, our research might provide potential research topics. For example, future researchers may focus on the possible solution to mitigate the losses from the asymmetric information.

To be sure, this study also has a limitation. Specifically, this study argues that the primary source of conflict among the principals is the asymmetric information. However, this paper lacks anecdotal evidences of this assumption which are needed to make our theory more persuasive.

Author Contributions: Conceptualization, K.-H.K. and K.-S.C.; formal analysis, K.-H.K. and K.-S.C.; methodology, K.-H.K. and K.-S.C.; validation, K.-H.K. and K.-S.C.; writing—original draft, K.-H.K. and K.-S.C.; writing-review \& editing, S.-W.Y.

Funding: This research received no external funding.

Conflicts of Interest: The authors declare no conflicts of interest.

\section{Appendix A}

Lemma A1. If we denote the agent's maximum amount of effort for the PI and WI principal as ePMAX and eWMAX, respectively,

$$
\text { ePMAX }_{\text {P }} \mathrm{e}_{\text {WMAX }}
$$

Proof. Note that $u^{\prime}{ }_{P}\left(e_{P M A X}\right)=u^{\prime}{ }_{W}\left(e_{W M A X}\right)=m$. Additionally, by Assumption $2, u^{\prime}{ }_{P}\left(e_{W M A X}\right)>m$. Recognizing that the principal's marginal payment decreases as the agent provides more effort for her, it naturally follows that $\mathrm{e}_{\mathrm{PMAX}}$ is always greater than $\mathrm{e}_{\mathrm{WMAX}}$.

Proof of Theorem 2(bi). Maximizing Equation (26) with respect to $e_{W}$ and $e_{P}$, the agent's individual effort for the PI and WI principal is given as $\mathrm{e}_{\mathrm{P}}{ }^{*}$ and $\mathrm{e}_{\mathrm{W}}{ }^{*}$, respectively. Equation (27) can be expressed as:

$$
\mathrm{u}^{\prime}{ }_{\mathrm{W}}\left(\mathrm{e}_{\mathrm{W}}^{*}\right)=\alpha \mathrm{m}+\left[\mathrm{u}_{\mathrm{P}}^{\prime}\left(\mathrm{e}_{\mathrm{W}}{ }^{*}\right)-\alpha \mathrm{u}_{\mathrm{P}}^{\prime}\left(\mathrm{e}_{\mathrm{W}}{ }^{*}\right)\right] .
$$


If we subtract $m$ from the right hand side of the Equation (27), the right hand side of the Equation (27) changes into:

$$
\alpha \mathrm{m}+\left[\mathrm{u}_{\mathrm{P}}^{\prime}\left(\mathrm{e}_{\mathrm{W}}{ }^{*}\right)-\alpha \mathrm{u}_{\mathrm{P}}^{\prime}\left(\mathrm{e}_{\mathrm{W}}^{*}\right)\right]-\mathrm{m}=\alpha\left[\mathrm{m}-\mathrm{u}_{\mathrm{P}}^{\prime}\left(\mathrm{e}_{\mathrm{W}^{*}}\right)\right]+\mathrm{u}_{\mathrm{P}}^{\prime}\left(\mathrm{e}_{\mathrm{W}}^{*}\right)-\mathrm{m} .
$$

Note that $\mathrm{e}_{\mathrm{WMAX}} \geq \mathrm{e}_{\mathrm{W}}{ }^{*}$. Thus, by Lemma 1, $\mathrm{e}_{\mathrm{PMAX}}>\mathrm{e}_{\mathrm{W}}{ }^{*}$. Since $\mathrm{e}_{\mathrm{PMAX}}=\mathrm{e}_{\mathrm{P}}{ }^{*}, \mathrm{e}_{\mathrm{P}}{ }^{*}>\mathrm{e}_{\mathrm{W}}{ }^{*}$. Based on the definition of the marginal willingness-to-pay function, it is definite that $u^{\prime}{ }_{\mathrm{P}}\left(\mathrm{e}_{\mathrm{W}^{*}}\right)$ is greater than $\mathrm{m}$. This implies that $\mathrm{m}-\mathrm{u}_{\mathrm{P}}^{\prime}\left(\mathrm{e}_{\mathrm{W}}{ }^{*}\right)<0$. Assuming $0<\alpha<1$, Equation (A2) is always positive. This establishes Theorem 2(bi).

Proof of Theorem 2(bii). See the Proof of Theorem 2(bi).

\section{References}

1. Laslo, Z.; Goldberg, A.I. Resource allocation under uncertainty in a multi-project matrix environment: Is organizational conflict inevitable? Int. J. Project Manag. 2008, 26, 773-788. [CrossRef]

2. Van der Merwe, A.P. Multi-project management—organizational structure and control. Int. J. Proj. Manag. 1997, 15, 223-233. [CrossRef]

3. Hendriks, M.H.A.; Voeten, B.; Kroep, L. Human resource allocation in a multi-project R\&D environment: Resource capacity allocation and project portfolio planning in practice. Int. J. Proj. Manag. 1998, 17, 181-188. [CrossRef]

4. Tong, T.K.L.; Tam, C.M. Fuzzy optimisation of labour allocation by genetic algorithms. Eng. Const. Archit. Manag. 2003, 10, 146-155. [CrossRef]

5. Wu, Y.K. On the manpower allocation within matrix organization: A fuzzy linear programming approach. Eur. J. Oper. Res. 2007, 183, 384-393. [CrossRef]

6. IBS Center for Management Research. Reorganizing ABB-From Matrix to Consumer-Centric Organization Structure (B). 2003. Available online: https://www.icmrindia.org/casestudies/catalogue/ Human\%20Resource\%20and\%20Organization\%20Behavior/Reorganizing\%20ABB-From\%20Matrix\% 20to\%20Consumer-Centric\%20Organization\%20Structure-B.htm (accessed on 4 November 2019).

7. Singh, N. Monitoring and hierarchies: The marginal value of information in a principal-agent model. J. Political Econ. 1985, 93, 599-609. [CrossRef]

8. Baron, D.P.; Besanko, D. Information, control, and organizational structure. J. Econ. Manag. Strategy 1992, 1, 237-275. [CrossRef]

9. Qian, Y. Incentives and loss of control in an optimal hierarchy. Rev. Econ. Stud. 1994, 61, 527-544. [CrossRef]

10. Ghemawat, P. Competitive advantage and internal organization: Nucor revisited. J. Econ. Manag. Strategy 1994, 3, 685-717. [CrossRef]

11. Laffont, J.; Martimort, D. The firm as a multicontract organization. J. Econ. Manag. Strategy 1997, 6, 201-234. [CrossRef]

12. Maskin, E.; Qian, Y.; Xu, C. Incentives, information, and organizational form. Rev. Econ. Stud. 2000, 67, 359-378. [CrossRef]

13. Harris, M.; Raviv, A. Organizational design. Manag. Sci. 2002, 48, 852-865. [CrossRef]

14. Norreen, E. The economics of ethics: A new perspective on agency theory. Account. Organ. Soc. 1988, 13, 359-369. [CrossRef]

15. Guenther, D. Measuring earnings management in response to corporate tax rate changes: Evidence from the 1986 Tax Reform Act. Account. Rev. 1994, 69, 230-243.

16. Maydew, E. Tax-induced earnings management by firms with net operating losses. J. Account. Res. 1997, 35, 83-96. [CrossRef]

17. Becker, C.L.; DeFond, M.L.; Jiambalvo, J.; Subramanyam, K.R. The effect of audit quality on earnings management. Contemp. Account. Res. 1998, 15, 1-24. [CrossRef]

18. Westphal, J. Collaboration in the boardroom: Behavior and performance consequences of CEO-board social ties. Acad. Manag. J. 1999, 42, 7-24. [CrossRef]

19. Healy, P.; Palepu, K. The fall of Enron. J. Econ. Perspect. 2003, 17, 3-26. [CrossRef] 
20. Butler, M.; Leone, A.J.; Willenborg, M. An empirical analysis of auditor reporting and its association with abnormal accruals. J. Account. Econ. 2004, 37, 139-165. [CrossRef]

21. Kothari, S.P.; Leone, A.J.; Wasley, C.E. Performance matched discretionary accrual measures. J. Account. Econ. 2005, 39, 163-197. [CrossRef]

22. Bae, G.S.; Choi, S.U.; Rho, J.H. Audit hours and unit audit price of industry specialist auditors: Evidence from Korea. Contemp. Account. Res. 2016, 33, 314-340. [CrossRef]

23. Bae, G.S.; Choi, S.U.; Dhaliwal, D.S.; Lamoreaux, P.T. Auditors and Client Investment Efficiency. Account. Rev. 2017, 92, 19-40. [CrossRef]

24. Gavana, G.; Gottardo, P.; Moisello, A. Earnings management and CSR disclosure. Family vs. non-family firms. Sustainability 2017, 9, 2327. [CrossRef]

25. Lizińska, J.; Czapiewski, L. Towards economic corporate sustainability in reporting: What does earnings management around equity offerings mean for long-term performance? Sustainability 2018, 10, 4349. [CrossRef]

26. Shawn, H.; Kim, Y.; Jung, J. Company's sustainability and accounting conservatism: Firms delisting from KOSDAQ. Sustainability 2019, 11, 1775. [CrossRef]

27. Aghion, P.; Tirole, J. Formal and real authority in organizations. J. Political Econ. 1997, 105, 1-29. [CrossRef]

28. Baker, G.; Gibbons, R.; Murphy, K.J. Informal authority in organizations. J. Law, Econ., Organ. 1999, 15, 56-73. [CrossRef]

29. Rajan, R.G.; Zingales, L. The firm as a dedicated hierarchy: A theory of the origins and growth of firms. Q. J. Econ. 2001, 116, 805-851. [CrossRef]

(C) 2019 by the authors. Licensee MDPI, Basel, Switzerland. This article is an open access article distributed under the terms and conditions of the Creative Commons Attribution (CC BY) license (http://creativecommons.org/licenses/by/4.0/). 